\title{
Reactive Oxygen Species Mediate Activity-Dependent Neuron-Glia Signaling in Output Fibers of the Hippocampus
}

\author{
Coleen M. Atkins and J. David Sweatt \\ Division of Neuroscience, Baylor College of Medicine, Houston, Texas 77030
}

Nonsynaptic signaling is becoming increasingly appreciated in studies of activity-dependent changes in the nervous system. We investigated the types of neuronal activity that elicit nonsynaptic communication between neurons and glial cells in hippocampal output fibers. High-frequency, but not lowfrequency, action potential firing in myelinated CA1 axons of the hippocampus resulted in increased phosphorylation of the oligodendrocyte-specific protein myelin basic protein (MBP). This change was blocked by tetrodotoxin, indicating that axonally generated action potentials were necessary to regulate the phosphorylation state of MBP. Furthermore, scavengers of the reactive oxygen species superoxide and hydrogen peroxide and nitric oxide synthase inhibitors prevented activation of this neuron-glia signaling pathway. These results indicate that, during periods of increased neuronal activity in area CA1 of the hippocampus, reactive oxygen and nitrogen species are generated, which diffuse to neighboring oligodendrocytes and result in post-translational modifications of MBP, a key structural protein in myelin. Thus, in addition to their well-known capacity for activity-dependent neuron-neuron signaling, hippocampal pyramidal neurons possess a mechanism for activitydependent neuron-glia signaling.

Key words: hippocampus; oligodendrocyte; glia; myelin; myelin basic protein; reactive oxygen species; superoxide; nitric oxide; hydrogen peroxide; alveus; neuron-glia signaling
Recent progress in studies of nonsynaptic cellular communication in the nervous system has illustrated the important role this form of signaling has during development, synaptic plasticity, and pathogenesis. This type of cellular communication has the power of a larger sphere of cellular influence than synaptic signaling, tends to have a long duration in its effects, and is not limited to cell types directly coupled by synaptic connections.

Several forms of nonsynaptic signaling have functional consequences in a variety of neuronal circuits, including electrotonic coupling by gap junctions, electric field effects, and signaling by diff usible molecules (Bach-y-Rita, 1993; Jefferys, 1995; Vanhatalo and Soinila, 1998). In the developing cortex, gap junctions mediate synchronous calcium oscillations to contribute to cortical column architecture (Connors et al., 1983; Peinado et al., 1993; Dermietzel, 1998). Electrical fields play a key role in synchronizing neuronal firing during interictal epileptic discharges (Snow and Dudek, 1984; Jefferys, 1995). Recently, reactive oxygen and nitrogen species have received considerable attention, because the diffusible messengers nitric oxide and superoxide have been found to modulate diverse forms of synaptic plasticity (Böhme et al., 1991; O’Dell et al., 1991, 1994; Shibuki and Okada, 1991; Haley et al., 1992; Daniel et al., 1993; Williams et al., 1993; Bito et al., 1996; Kantor et al., 1996; Son et al., 1996; Wilson et al., 1997; Gahtan et al., 1998; Klann et al., 1998).

One form of synaptic plasticity well studied in the context of nonsynaptic cellular signaling is hippocampal long-term potentiation (LTP), which is a persistent increase in synaptic efficacy

Received March 30, 1999; revised May 24, 1999; accepted June 9, 1999.

This work was supported by National Institutes of Health Grant MH 57014 (J.D.S.) and a Williams Stamps Farish graduate fellowship (C.M.A.). We thank J. P. Adams, A. E. Anderson, C. M. Kondratick, B. Mirnikjoo, and J. C. Selcher for critical reading of this manuscript.

Correspondence should be addressed to J. David Sweatt, Division of Neuroscience, Baylor College of Medicine, One Baylor Plaza, Houston, TX 77030.

Copyright (C) 1999 Society for Neuroscience $0270-6474 / 99 / 197241-08 \$ 05.00 / 0$ elicited by brief, high-frequency stimulation. LTP induced by modest tetanic stimulation is inhibited by nitric oxide synthase inhibitors, whereas strong LTP-inducing stimulation can mitigate this inhibition (Chetkovich et al., 1993; O’Dell et al., 1994; Williams et al., 1993; Kantor et al., 1996; Son et al., 1996; Wilson et al., 1997; Gahtan et al., 1998; Klann et al., 1998). Interestingly, an adjacent nonsynaptically connected neuron can express LTP when LTP is induced in a neighboring neuron (Schuman and Madison, 1994). This requires nitric oxide synthase activity, providing compelling evidence that nitric oxide can act as an intercellular messenger during LTP. It has been proposed that reactive oxygen and nitrogen species act by activating protein kinase $\mathrm{C}$ (PKC) and mitogen-activated protein kinase (MAPK) during LTP because these enzymes are required for LTP and are activated by reactive oxygen species in the hippocampus (Roberson et al., 1996; Klann et al., 1998).

Recently, we observed an increase in myelin basic protein (MBP) phosphorylation by PKC during hippocampal CA1 LTP (Atkins et al., 1997). These results are intriguing, because MBP, a key structural protein in myelin of the CNS, is located only in myelinating oligodendrocytes and Schwann cells (Hartman et al., 1979). If we assume that LTP is induced neuronally, then these findings suggest that neurons and oligodendrocytes communicate nonsynaptically during periods of increased neuronal activity. The present study investigates this novel form of nonsynaptic neuron-glia signaling in the hippocampus.

\section{MATERIALS AND METHODS}

Hippocampal slice preparation. Standard hippocampal slice preparations were prepared as described previously(Roberson and Sweatt, 1996). All experiments were performed in compliance with the Baylor College of Medicine Institutional Animal Care and Use Committee and national regulations and policies. The alveus was stimulated antidromically, and extracellular field recordings were made in stratum pyramidale of the CA1 region. The amplitude of the population spike was measured. Low-frequency stimulation (LFS) $(0.05 \mathrm{~Hz})$ was delivered at a stimulus 
intensity $30-40 \%$ of the maximum response. High-frequency stimulation (HFS) consisted of three sets of tetani (two $100 \mathrm{~Hz}$, 1-sec-long tetani, separated by $20 \mathrm{sec}$ ) separated by 5 min given at the minimum stimulation intensity that elicited $75 \%$ of the maximum response. Forty-five minutes after delivery of the final tetani, the hippocampal slices were frozen on dry ice, and CA1 regions were microdissected. For experiments in which calcium was omitted from the saline, magnesium concentrations were increased to $6 \mathrm{~mm}$.

MBP phosphorylation assay. To assess changes in the phosphorylation state of MBP, a back-phosphorylation assay was performed as described previously (Atkins et al., 1997). Hippocampal CA1 regions were homogenized in buffer (50 mM Tris-HCl, pH 7.5, 1 mm EGTA, 1 mm EDTA, 2 $\mathrm{mM} \mathrm{Na} \mathrm{P}_{2} \mathrm{O}_{7}, 10 \mu \mathrm{g} / \mathrm{ml}$ aprotinin, $10 \mu \mathrm{g} / \mathrm{ml}$ leupeptin, and $100 \mu \mathrm{M}$ phenylmethylsulfonyl fluoride) and boiled for $10 \mathrm{~min}$ at $95^{\circ} \mathrm{C}$. To backphosphorylate MBP, exogenous PKC (purified according to the method of Huang et al., 1986), $\mathrm{CaCl}_{2}(1.5 \mathrm{~mm}), 1-\alpha$-phosphatidylserine (320 $\mu \mathrm{g} / \mathrm{ml}), 1,2$-dioctanoyl-sn-glycerol $(30 \mu \mathrm{g} / \mathrm{ml}),\left[\gamma^{-32}{ }^{32}\right]$ ATP $(20 \mu \mathrm{M}, 10$ $\mu \mathrm{Ci} /$ reaction), and $\mathrm{MgCl}_{2}(10 \mathrm{~mm})$ were added to the homogenate. Reactions were performed at $37^{\circ} \mathrm{C}$ for $10-60$ min for stoichiometric phosphorylation of MBP. Proteins were separated by 15\% SDS-PAGE, and phosphorylation was assessed by densitometric analysis of autoradiographs. Changes in MBP phosphorylation and amount in experimental slices were normalized to control levels measured in paired hippocampal slices from the same preparation and recording chamber. Control slices received three brief test stimulations to ensure viability.

Western blotting. Western blots and densitometric analyses were performed as described previously (Atkins et al., 1997). The following primary antibodies were used: total MBP [1:1000 (Chemicon, Temecula, CA) or 1:2000 (Boehringer Mannheim, Indianapolis, IN)] and total MAPK (1:1000; Upstate Biotechnology, Lake Placid, NY). To measure changes in MBP phosphorylation, phosphorylation levels were normalized against total MBP amounts and then against total protein levels using p44 MAPK immunoreactivity or a Lowry assay. To measure changes in MBP amounts, immunoreactivity using a primary antibody that detects MBP regardless of the phosphorylation state of the protein was normalized against p44 MAPK immunoreactivity or a Lowry assay.

Materials. Phorbol diacetate (PDA), picrotoxin, bicuculline, 5,5dimethylpyrroline 1-oxide (DMPO), $N$-nitro-L-arginine (L-NOArg), and $N$-monomethyl-L-arginine (L-NMMA) were from Sigma (St. Louis, MO). 6-Cyano-7-nitro-quinoxaline 2,3-(1H,4H)-dione (CNQX), DL-2amino-5-phosphonovalerate (APV), 2-hydroxysaclofen, and RS- $\alpha$-methyl4-carboxyphenylglycine (MCPG) were from Tocris Cookston (Ballwin, MO). Tetrodotoxin (TTX) was from Research Biochemicals (Natick, MA). Superoxide dismutase (SOD) and catalase were from Calbiochem (Pasadena, CA). This preparation of catalase has been reported previously to be free from contaminating arginase activity (Esch et al., 1998).

\section{RESULTS}

\section{Antidromic stimulation of CA1 axons in the alveus}

The alveus is the final output pathway in the hippocampus, an area of the brain critical for information processing (Milner et al., 1998). In these studies, we investigated neuron-glia signaling in the alveus for several reasons. First, the hippocampal slice preparation is easily accessible for electrically triggering action potentials in myelinated axons (Fig. $1 A$ ). Second, this preparation is also amenable to pharmacological manipulations. Third, the alveus is the locus for MBP-containing oligodendrocytes in area CA1 of the hippocampus (Westrum and Blackstad, 1962; Andersen, 1975; Tamamaki and Nojyo, 1991). Therefore, using this preparation, we can assay for alterations in MBP as an index of intracellular changes in oligodendrocytes that occur in response to changes in neuronal activity elicited by stimulation of CA1 pyramidal cell axons.

To isolate the effects of nonsynaptic signaling, we performed all hippocampal slice experiments in the presence of fast synaptic transmission blockers (Fig. $1 B$ ). When electrical stimulation was delivered to the alveus and extracellular recordings were made in stratum pyramidale of area CA1, we measured a population spike whose amplitude correlated with stimulus intensity (Fig. 1C). Thus, stimulation of CA1 pyramidal neurons in the absence of fast synaptic transmission produced measurable back-propagating action potentials (Fig. 1D).

With this preparation, we assessed activity-dependent neuronglia signaling by assaying for changes in the oligodendrocytespecific protein MBP. To measure MBP phosphorylation, we used a back-phosphorylation assay with PKC. Because there are no phospho-specific antibodies against PKC phosphorylation sites of MBP, we used the back-phosphorylation assay, which allows for detection of the phosphorylation state of proteins in situ. We have identified previously the $18.5 \mathrm{kDa}$ isoform of MBP by amino acid sequencing, phospho-peptide mapping, Western blotting, and immunoprecipitation (Atkins et al., 1997). The identity of MBP was confirmed for this study by phospho-peptide mapping (Fig. $2 A$ ). In initial experiments, we determined whether we could detect changes in MBP phosphorylation with the backphosphorylation assay after stimulating PKC activity in hippocampal slices with $10 \mu \mathrm{M}$ PDA. PDA treatment of slices resulted in a significant decrease in $\left[{ }^{32} \mathrm{P}\right]$ phosphate incorporation into MBP with the back-phosphorylation assay (Fig. $2 B$ ), reflecting an increase in the phosphorylation state of MBP in situ. Thus, having identified MBP and demonstrating that we could observe changes in MBP phosphorylation in situ with the backphosphorylation assay, we assayed for changes in MBP phosphorylation after alveus stimulation. We investigated the effects of two physiology paradigms, LFS and HFS, on MBP phosphorylation.

\section{High-frequency stimulation is required for neuron-glia signaling}

For experiments in which LFS was delivered to the alveus, we used either a low or high stimulus intensity to determine if either would elicit neuron-glia communication. The results obtained using these two stimulus intensities were not significantly different (data not shown) and were pooled (Fig. 2C). LFS had no effect MBP phosphorylation levels. Thus, action potential firing at low frequencies (i.e., $0.05 \mathrm{~Hz}$ ) does not activate a neuron-glia signaling pathway that results in regulation of MBP phosphorylation.

In contrast, HFS elicited a significant increase in MBP phosphorylation in situ. Forty-five minutes after HFS of the alveus, there was a significant decrease in $\left[{ }^{32} \mathrm{P}\right]$ phosphate incorporation into the $18.5 \mathrm{kDa}$ isoform of MBP (Fig. 2C,D). These results indicate that MBP phosphorylation levels increase as a result of high-frequency action potential firing in CA1 neurons.

The back-phosphorylation assay allows for quantitative assessment of protein phosphorylation levels if absolute basal phosphorylation levels of protein are known. In a separate series of studies to determine the absolute stoichiometry of MBP phosphorylation, we found that the basal level of MBP phosphorylation in the rat hippocampus is $36 \pm 1 \%(n=3)$ of total MBP phosphorylation sites. Therefore, the observed relative decrease in MBP back-phosphorylation in our HFS studies, which is a $22 \%$ relative decrease in phosphorylation at PKC sites, represents approximately an absolute $14 \%$ increase in phosphate incorporation into MBP in the cell. This suggests that PKC phosphorylation of MBP in situ increased from 36 to $50 \%$ of total phosphorylation sites as a consequence of high-frequency neuronal firing. A selective inhibitor of PKC, chelerythrine $(33 \mu \mathrm{M})$ (Herbert et al., 1990), blocked the increase in MBP phosphorylation, indicating that PKC was the likely kinase phosphorylating MBP in situ (MBP phosphorylation, $119 \pm 21 \%$ of control; $n=7$; MBP amount, $94 \pm 11 \%$ of control; $n=7$ ). These results suggest that high-frequency action potentials in the alveus activate a neuron- 
A

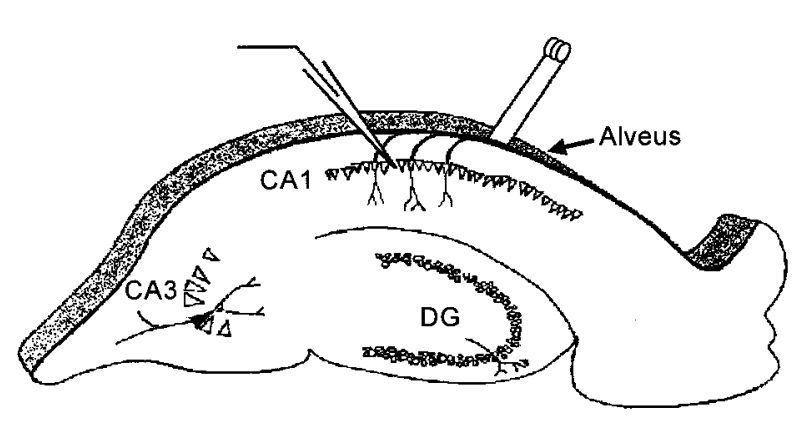

B

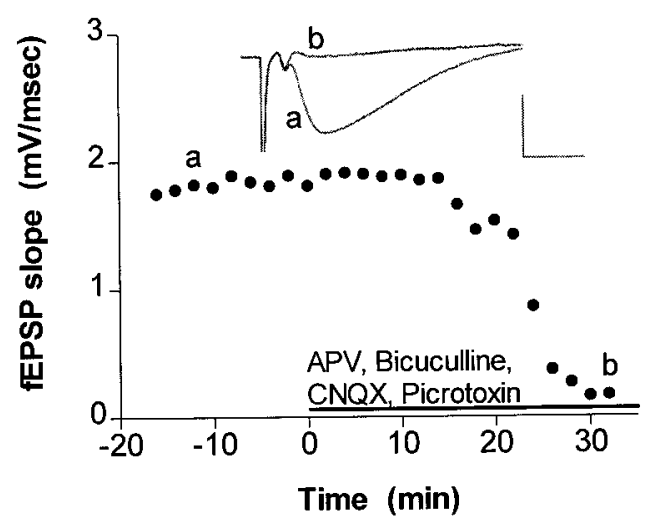

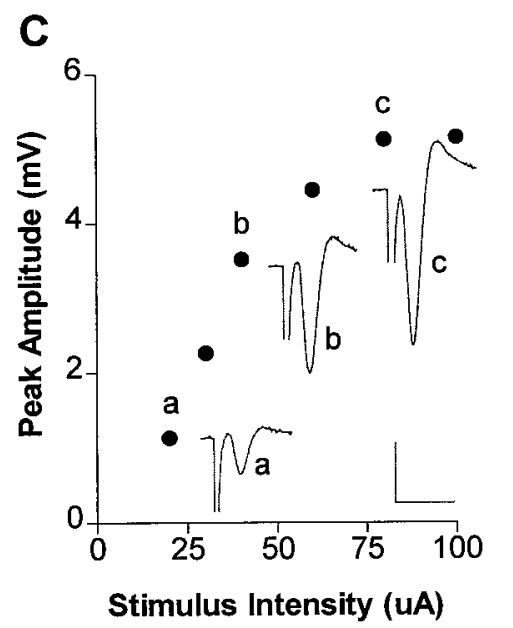

D

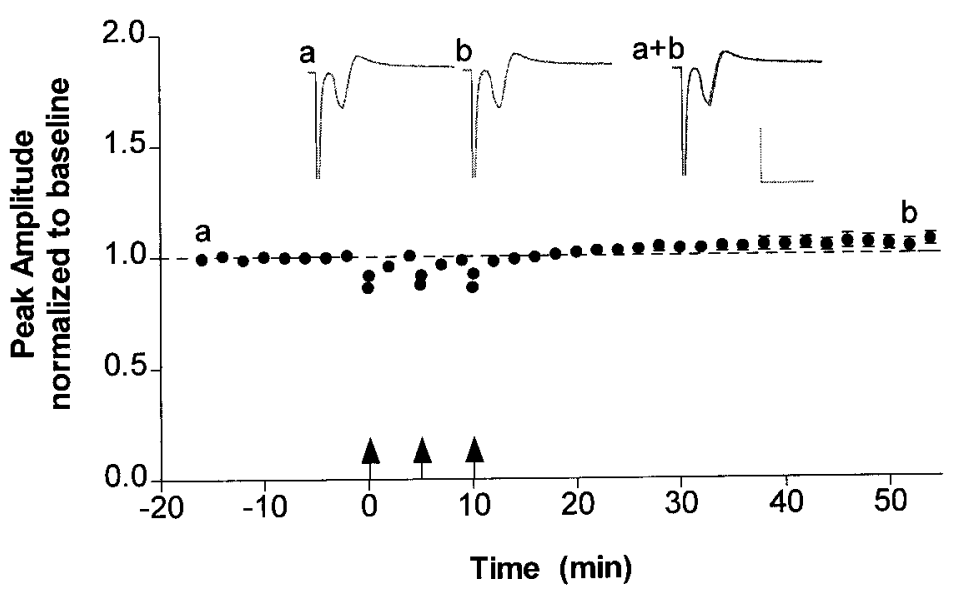

Figure 1. Low- and high-frequency alvear stimulation of the hippocampus was assessed to determine the forms of neuronal activity that elicit neuron-glia signaling. $A$, Schematic representation of the hippocampal slice preparation used in our experiments. A stimulating electrode was placed in the alveus, and action potentials were monitored with an extracellular recording electrode placed in stratum pyramidale of the CA1 region. $B$, To assess whether fast synaptic transmission was blocked in all our experiments, we first recorded field EPSP (fEPSP) responses in stratum radiatum in response to Schaffer collateral-commissural pathway stimulation. The fast synaptic transmission blockers CNQX $(20 \mu \mathrm{M})$, APV $(50 \mu \mathrm{M})$, picrotoxin $(20 \mu \mathrm{M})$, and bicuculline $(20 \mu \mathrm{M})$ were applied (solid bar), and the fEPSP was monitored until it was completely abolished. Traces represent the response before ( $a$ ) and after $(b)$ drug application. $C$, Before all physiology experiments in the alveus, we obtained an $I-O$ curve by measuring the peak amplitude of the population spike with increasing stimulus intensity. Representative traces at $20(a), 40(b)$, and $80(c) \mu \mathrm{A}$ are shown. $D$, To study neuron-glia communication during increased firing of CA1 neurons, we delivered HFS (arrows) to the alveus after acquiring a baseline (16 min) and monitored the population spike in stratum pyramidale of the CA1 region $(n=9)$ for $45 \mathrm{~min}$ after the final tetanus. The corresponding physiology traces before $(a)$ and after $(b)$ tetanization are shown in the inset. Calibration: $2 \mathrm{msec}, 4 \mathrm{mV}$.

glia signaling pathway that leads to a long-lasting, significant regulation of $\mathrm{MBP}$ phosphorylation.

\section{Necessity of action potentials}

In the preceding experiments, we delivered all electrical stimulation directly to the alveus; thus direct stimulation of nearby oligodendrocytes could possibly account for the regulation of MBP phosphorylation. To eliminate this possibility, we determined whether action potentials in neurons are necessary for the change in MBP phosphorylation. We applied TTX to hippocampal slices and then delivered HFS and assayed the CA1 subregions 45 min later. Voltage-gated sodium channels are not present on mature oligodendrocytes (Barres et al., 1988; Soliven et al., 1988; Sontheimer et al., 1989; Berger et al., 1991); therefore, TTX should block axonal firing but leave direct stimulation of oligodendrocytes intact (Fig. $3 A$ ). Although there are proton-activated sodium channels on oligodendrocytes, these are insensitive to
TTX and voltage (Sontheimer et al., 1989). As expected, TTX application blocked firing of CA1 pyramidal neurons (Fig. $3 A$ ). The change in MBP phosphorylation was also inhibited by TTX (Fig. 3B,C), demonstrating that direct oligodendrocyte stimulation is not sufficient to explain the change in the phosphorylation state of MBP. Therefore, action potential generation in axons is required for $\mathrm{MBP}$ to be modulated by high-frequency firing in the alveus.

\section{Four MBP isoforms are regulated by neuron-glia signaling}

The low molecular weight, classical MBPs exist as a family of isoforms ranging from 14 to $21.5 \mathrm{kDa}$ (Monuki and Lemke, 1995). In the previous experiment, we choose to assay for the $18.5 \mathrm{kDa}$ isoform because we have identified previously this protein by amino acid sequencing, phospho-peptide mapping, Western blotting, and immunoprecipitation (Fig. 2A) (Atkins et al., 1997). To 
A
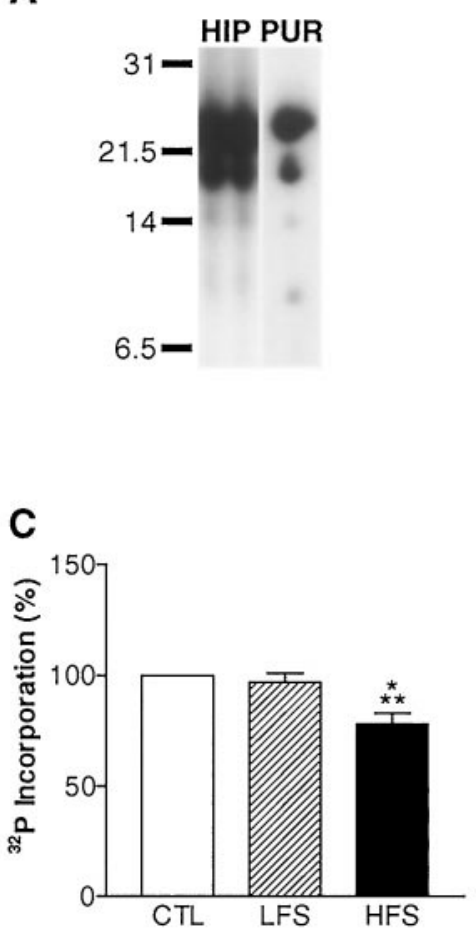

Figure 2. MBP phosphorylation during neuron-glia signaling in the alveus was assessed by back-phosphorylation (Atkins et al., 1997). A, MBP was identified on autoradiographs by comparing the phosphopeptide maps of MBP in the rat hippocampus (HIP) (shown in two lanes to facilitate comparison) with purified MBP (PUR) identified by amino acid sequencing (Atkins et al., 1997). Accordingly, if hippocampal slices were back-phosphorylated without the alveus, we observed a marked reduction in MBP amounts (data not shown). B, Activation of PKC by PDA applied for $5 \mathrm{~min}$ to hippocampal slices results in an observable increase in MBP phosphorylation in the back-phosphorylation assay. A representative autoradiograph is shown of a vehicle-treated $(C T L, 0.01 \%$ DMSO) and a PDA-treated (PDA) hippocampal CA1 subregion subjected to back-phosphorylation. MBP is denoted by the arrow. In the backphosphorylation assay, increases in phosphorylation are manifested as decreases in $\left[{ }^{32} \mathrm{P}\right]$ phosphate incorporation. $C$, Densitometric analysis of autoradiographs revealed no significant change in MBP phosphorylation after delivery of LFS throughout the duration of the experiment $(75 \mathrm{~min}$; $n=13)$. However, a significant increase in MBP phosphorylation was observed $45 \mathrm{~min}$ after tetanization of the alveus $(78 \pm 5 \%$ of control; $n=$ $14 ; p<0.001$; ANOVA). Similar results were also observed when the slow synaptic transmission blockers MCPG and 2-hydroxysaclofen were included to block metabotropic glutamate and $\mathrm{GABA}_{\mathrm{B}}$ - mediated synaptic transmission ( $77 \pm 13 \%$ of control; $n=3$ ). There was no change in MBP amounts in HFS slices $(116 \pm 11 \%$ of control; $n=12)$ or LFS slices $(113 \pm 5 \%$ of control; $n=14)$. $D$, A representative autoradiograph is shown of a hippocampal slice that received HFS of the alveus (HFS) compared with a paired control slice $(C T L)$ that were assayed by backphosphorylation for changes in MBP phosphorylation in the CA1 subregion.

determine whether other isoforms of MBP are regulated during increased neuronal firing, we also assayed for changes in the 14, 17 , and $21.5 \mathrm{kDa}$ isoforms. To identify each isoform, we compared the apparent molecular weights of the MBP isoforms on autoradiographs with Western blots that detected all four isoforms (Atkins et al., 1997). We found that all four MBP isoforms were regulated by phosphorylation as a consequence of HFS of the alveus (Fig. 4). This finding strengthens our assertion that these biochemical changes elicited by neuronal activity are occurring in oligodendrocytes. All further experiments entailed anal-
A
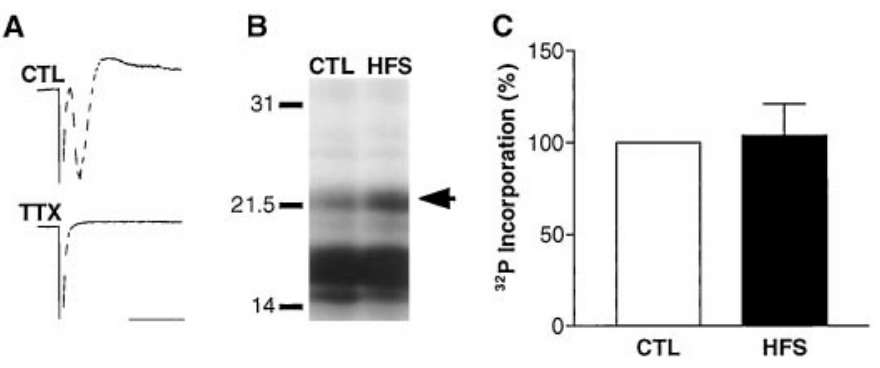

Figure 3. The increase in MBP phosphorylation requires action potentials in CA1 axons. $A$, When TTX (500 nM) was applied to hippocampal slices, the population spike in stratum pyramidale was completely abolished (TTX). A representative control response is shown for comparison $(C T L)$. Calibration: $2 \mathrm{msec}, 4 \mathrm{mV}$. B, Tetanization of the alveus in the presence of TTX abolished the increase in MBP phosphorylation as shown by the representative autoradiograph. $C$, This was confirmed by the corresponding densitometric analysis (HFS) $(n=7)$. We did not observe any changes in MBP amount with this protocol (91 $\pm 8 \%$ of control; $n=$ 11). Thus, action potentials generated in CA1 axons are necessary for neuron-glia signaling.

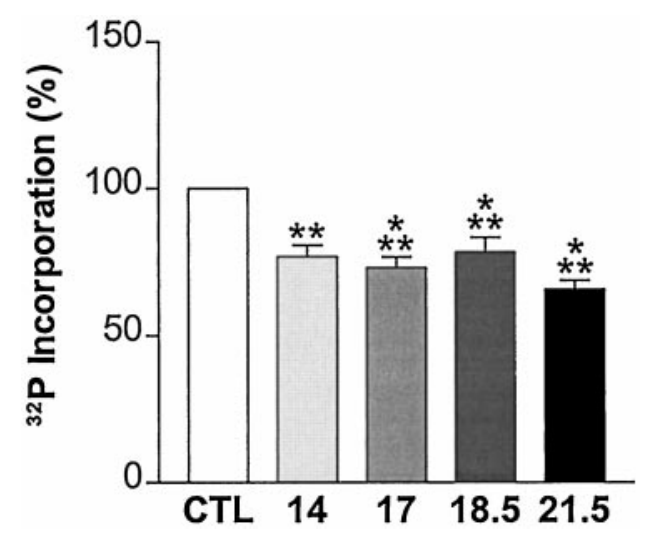

Figure 4. Four isoforms of $\operatorname{MBP}(14,17,18.5$, and $21.5 \mathrm{kDa})$ are regulated by phosphorylation during periods of increased activity of CA1 neurons. Each isoform was identified by comparison of Western blots with autoradiographs, with the exception of the $18.5 \mathrm{kDa}$ isoform, which was identified by amino acid sequencing and phospho-peptide mapping (Atkins et al., 1997). Densitometric analysis of autoradiographs from hippocampal slices that received HFS of the alveus compared with control slices demonstrates increased phosphorylation of all four MBP isoforms $(14 \mathrm{kDa}, n=6 ; p<0.01 ; 17 \mathrm{kDa}, n=9 ; p<0.001 ; 18.5 \mathrm{kDa}, n=14 ; p<$ $0.001 ; 21.5 \mathrm{kDa}, n=9 ; p<0.001$; ANOVA).

ysis of the $18.5 \mathrm{kDa}$ isoform because we have conclusively identified this protein in previous experiments (Atkins et al., 1997).

\section{Identification of the transcellular messenger(s)}

Several observations in the literature suggested that the signaling molecule mediating the communication between neurons and oligodendrocytes in the alveus could be a diffusible messenger, such as nitric oxide or superoxide. First, neuronal activitydependent generation of reactive oxygen and nitrogen species has been observed in the hippocampus (Chetkovich et al., 1993; Bindokas et al., 1996; Bito et al., 1996). Second, nitric oxide and superoxide modulate the induction of LTP in the CA1 region of the hippocampus, suggesting that these diffusible messengers are intercellular messengers during periods of increased neuronal activity (Böhme et al., 1991; O’Dell et al., 1991, 1994; Haley et al., 1992; Chetkovich et al., 1993; Williams et al., 1993; Kantor et al., 1996; Son et al., 1996; Wilson et al., 1997; Gahtan et al., 1998; Klann et al., 1998). Third, the change in MBP phosphorylation is 
A

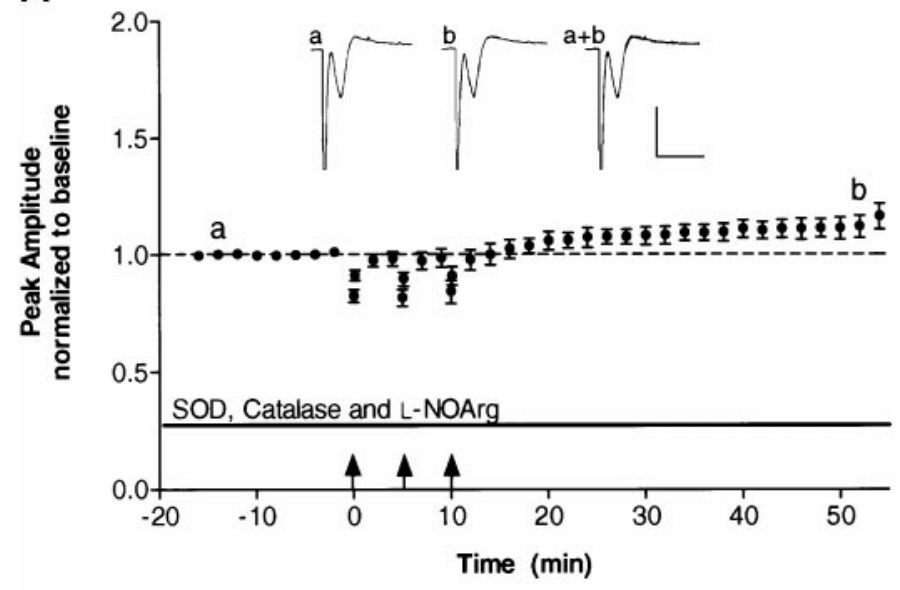

B
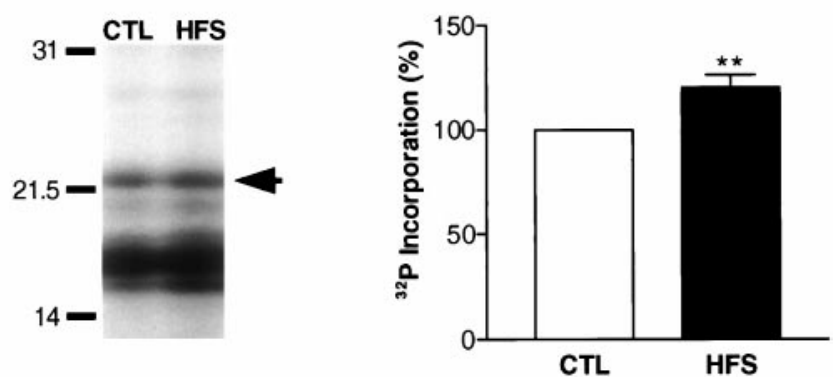

Figure 5. Reactive oxygen species scavengers and a nitric oxide synthase inhibitor block the increase in MBP phosphorylation during neuron-glia signaling. A, Hippocampal slices were perfused with SOD (120 U/ml), catalase $(260 \mathrm{U} / \mathrm{ml})$, and L-NOArg $(50 \mu \mathrm{M})$ in the recording saline throughout the experiment. After 16 min of baseline recording, the alveus was tetanized (arrows), and then $45 \mathrm{~min}$ after the final tetanus, the CA1 subregion was assayed for changes in MBP phosphorylation and amount. Inset traces were obtained before $(a)$ and after $(b)$ tetanization. Calibration: $2 \mathrm{msec}, 4 \mathrm{mV}$. $B$, Representative autoradiograph of a control and HFS slice demonstrates an increase in $\left[{ }^{32} \mathrm{P}\right]$ phosphate incorporation in the HFS slice, indicating decreased phosphorylation of MBP in situ. Densitometric analysis confirmed these results. There was a small but significant decrease in MBP phosphorylation when reactive oxygen species scavengers and a nitric oxide synthase inhibitor was applied to slices $(n=6 ; p<0.01$; Student's $t$ test) with no change in MBP amounts (96 \pm $21 \%$ of control; $n=6$ ).

mediated by $\mathrm{PKC}$, and reactive oxygen species increase the activity of PKC in vitro (Gopalakrishna and Anderson, 1989; Larsson and Cerutti, 1989; Palumbo et al., 1992) and during hippocampal LTP (Klann et al., 1998). As an initial test of the hypothesis that a reactive oxygen or nitrogen species was the signal mediating neuron-glia communication, we applied a combination of SOD (a superoxide scavenging enzyme), catalase (a hydrogen peroxide scavenger), and L-NOArg (a nitric oxide synthase inhibitor) to hippocampal slices. Forty-five minutes after HFS of the alveus, the CA1 subregions were assayed for changes in MBP phosphorylation (Fig. $5 A$ ). We found that SOD, catalase, and L-NOArg applied together blocked the increase in MBP phosphorylation and, in fact, decreased MBP phosphorylation levels (Fig. 5B). These results demonstrate that the activitydependent changes in oligodendrocytes are blocked by reactive oxygen species scavengers and a nitric oxide synthase inhibitor. In addition, because MBP phosphorylation levels are decreased, this

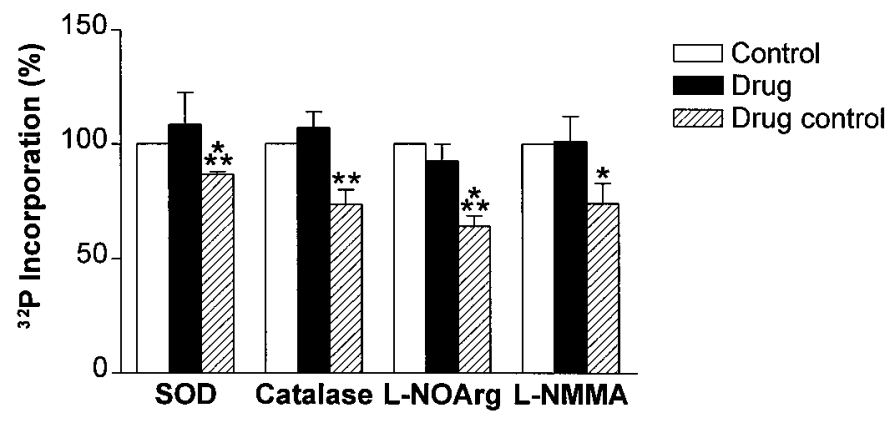

Figure 6. Superoxide, hydrogen peroxide, and nitric oxide each can mediate the signal between CA1 neurons and oligodendrocytes in the alveus during periods of increased action potential firing. Application of each scavenger or inhibitor alone (solid bars) blocked the increase in MBP phosphorylation (SOD, $120 \mathrm{U} / \mathrm{ml} ; n=6$; catalase, $260 \mathrm{U} / \mathrm{ml} ; n=6$; L-NOArg, $50 \mu \mathrm{M} ; n=9$; L-NMMA, $30 \mu \mathrm{M} ; n=4)$. However, application of the inactive forms of these inhibitors (hatched bars) did not block the increase in MBP phosphorylation after tetanization of the alveus (boiled SOD, $120 \mathrm{U} / \mathrm{ml} ; n=5 ; p<0.001$; Student's $t$ test; boiled catalase, 260 $\mathrm{U} / \mathrm{ml} ; n=6 ; p<0.01$; ANOVA; D-NOArg, $50 \mu \mathrm{M} ; n=5 ; p<0.001$; ANOVA; D-NMMA, $30 \mu \mathrm{M} ; n=6 ; p<0.05$; ANOVA). There was a small increase in MBP amounts in slices administered boiled catalase or D-NMMA (boiled catalase, $120 \pm 6 \%$ of control; $n=6 ; p<0.01$; Student's $t$ test; D-NMMA, $117 \pm 6 \%$ of control; $n=6 ; p<0.05$; Student's $t$ test) but not with any other drug treatment (SOD, $114 \pm 19 \%$ of control; $n=6$; boiled SOD, $106 \pm 6 \%$ of control; $n=6$; catalase, $94 \pm$ $9 \%$ of control; $n=6$; L-NOArg, $112 \pm 11 \%$ of control; $n=9$; D-NOArg, $117 \pm 9 \%$ of control; $n=5 ;$ L-NMMA, $100 \pm 9 \%$ of control; $n=4)$.

result suggests that protein phosphatase activation or protein kinase inhibition during neuron-glia signaling is unmasked by inhibition of these reactive oxygen and nitrogen species. Thus, the reactive oxygen and nitrogen species superoxide, hydrogen peroxide, or nitric oxide (or all three) could be the transcellular signal between neurons and glial cells.

To determine which reactive oxygen or nitrogen species was necessary for neuron-glia signaling, we applied each of these scavengers and inhibitors separately to hippocampal slices and assayed for changes in MBP phosphorylation (Fig. 6). Application of SOD or catalase alone blocked the increase in MBP phosphorylation whereas boiled, inactivated SOD or catalase had no effect. Another superoxide scavenger, DMPO (10 mM), also blocked the increase in the phosphorylation state of MBP $(98 \pm 16 \%$ of control; $n=6$ ). The nitric oxide synthase inhibitors L-NOArg or L-NMMA blocked the increase in MBP phosphorylation as well (Fig. 6). The inactive enantiomers of these inhibitors had no effect. From these results, we conclude that superoxide, hydrogen peroxide, and nitric oxide each are required for neuron-glia signaling during high-frequency action potential firing.

Given these results, we propose that the source of reactive oxygen species in axons could be nitric oxide synthase. Nitric oxide synthase produces nitric oxide, as well as superoxide in a calcium-calmodulin-dependent manner (Pou et al., 1992; Xia et al., 1996, 1998). Furthermore, the interconvertability of superoxide with hydrogen peroxide may account for the observation that inhibitors of either of these reactive oxygen species blocked neuron-glia signaling (Halliwell, 1992). Nitric oxide synthase has been reported to be found in axons (Dinerman et al., 1994; Wendland et al., 1994; De Vente et al., 1998); thus, we hypothesized that high-frequency action potential propagation resulted in activation of axonal nitric oxide synthase. As an initial test of this hypothesis, we determined whether extracellular calcium was necessary for neuron-glia signaling by omitting extracellular cal- 
cium from the saline. When CA1 subregions were assayed for changes in MBP phosphorylation after HFS of the alveus, there was no change in the phosphorylation state of MBP $(103 \pm 21 \%$ of control; $n=7)$ or amount $(93 \pm 18 \%$ of control; $n=7)$. This result indicates that extracellular calcium is necessary for neuron-glia signaling in the alveus.

\section{DISCUSSION}

In these studies, we have discovered a signaling pathway between neurons and glial cells in the hippocampus that is activated during periods of increased neuronal activity. Our studies suggest that high-frequency action potential propagation in the output fibers of the hippocampus generates a reactive oxygen or nitrogen species that diffuses to the surrounding myelin sheath and activates $\mathrm{PKC}$ to regulate MBP phosphorylation. The effects of high-frequency action potential firing are long-lasting, at least 45 min beyond the period of increased neuronal activity. Thus, the hippocampus possesses not only a mechanism to elicit long-lasting activity-dependent changes in neurons by synaptic signaling (i.e., LTP), it also possesses a mechanism for long-lasting activitydependent changes in glia by reactive oxygen species-mediated signaling.

\section{Reactive oxygen and nitrogen species as neuron-glia messengers}

Our experiments demonstrate that superoxide, hydrogen peroxide, and nitric oxide are all involved in neuron-glia communication in the hippocampus. An interesting finding was that application of SOD, catalase, or DMPO blocked the changes in MBP phosphorylation. These reactive oxygen species scavengers are membrane-impermeant, suggesting that they blocked the signaling of a diff usible molecule that traversed the extracellular space to signal from axons to oligodendrocytes. Because SOD and DMPO are extracellular scavengers of superoxide, we must hypothesize that superoxide, a negatively charged species, diff used from axons across the extracellular space and into the myelin sheath. Studies have found that superoxide is permeant to biological membranes (Lynch and Fridovich, 1978; Rumyantseva et al., 1979; Mao and Poznansky, 1992). Alternatively, it is possible that superoxide may have dismutated to form hydrogen peroxide (Halliwell, 1992) and traversed the membrane in this form, or reacted with nitric oxide to form peroxynitrite, which decomposed to a membrane-permeant species with hydroxyl radical character (Beckman et al., 1990; Radi et al., 1991; Halliwell, 1992; Huie and Padmaja, 1993). Transition metals, such as copper or iron, convert superoxide and hydrogen peroxide into the highly reactive hydroxyl radical (Halliwell, 1992). Iron in the brain is typically bound to ferritin and transferrin and is found in high concentrations in oligodendrocytes (Gerber and Connor, 1989; Connor et al., 1992). Thus, once superoxide or hydrogen peroxide cross into the oligodendrocyte, they have the potential of becoming even more reactive by conversion into the hydroxyl radical. Because the chemistry of these reactive oxygen species is so tightly interwoven, it is difficult to definitively identify the biochemical nature of the reactive oxygen species involved in this signaling pathway.

\section{Reaction oxygen species generation by neuron-glia signaling}

In our model, we propose that the reactive oxygen and nitrogen species are generated from axonally located nitric oxide synthase, a calcium-calmodulin-sensitive enzyme (Dinerman et al., 1994; Wendland et al., 1994; De Vente et al., 1998). Calcium can enter axons through sodium channels or reversal of the sodium-calcium transporter (Mullins et al., 1985; DiPolo and Beauge, 1987; Waxman and Ritchie, 1993; Stys and Lopachin, 1998). Sodium channels are very abundant at the node of Ranvier $\left(\sim 1000 \mu \mathrm{m}^{2}\right)$, and their permeability ratio of $\mathrm{P}_{\mathrm{Ca}} / \mathrm{P}_{\mathrm{Na}}$ is between $1: 10$ and $1: 7$ (Meves and Vogel, 1973; Waxman and Ritchie, 1993). The sodium-calcium exchanger removes calcium intracellularly in exchange for sodium using the electrochemical gradient of sodium (Mullins et al., 1985; DiPolo and Beauge, 1987; Stys and Lopachin, 1998). When the sodium gradient across the membrane diminishes or reverses, the gradient can reverse, transporting calcium intracellularly and removing sodium from the cytoplasmic space. Thus, calcium flux through either of these pathways could be involved in activating nitric oxide synthase.

Although nitric oxide synthase is one potential source for the generation of the reactive oxygen species in this pathway, there are several other potentially relevant sources. These include arachidonic acid metabolism, xanthine oxidase, and the mitochondrial electron transport chain. Arachidonic acid metabolism has already been implicated in hippocampal signaling as a lipoxygenase inhibitor, nordihydroguaiaretic acid, inhibits LTP (Lynch et al., 1989; Williams and Bliss, 1989; O’Dell et al., 1991), and arachidonic acid metabolism increases during LTP (Lynch et al., 1989, 1991). Xanthine oxidase, another potential source of superoxide, catalyzes the conversion of xanthine to uric acid, reducing molecular oxygen, which generates superoxide (McCord, 1985). Xanthine oxidase can be proteolytically generated by a calciumactivated protease (McCord, 1985), consistent with the requirement for extracellular calcium. Alternatively, a rise in mitochondrial respiration may increase the leakage of electrons, producing superoxide (Fridovich, 1978, 1989). Interestingly, glutamate receptor agonists produce superoxide in hippocampal slices, and this increase in superoxide was visualized to be near mitochondria (Bindokas et al., 1996). In summary, axonally located nitric oxide synthase, arachidonic acid metabolism, proteolytic conversion of xanthine oxidase, and the mitochondrial electron transport chain are all potential sources of reactive oxygen and nitrogen species during neuron-glia signaling. Further experiments are required to conclusively determine the source of the reactive oxygen species that is generated during neuron-glia signaling.

What is the redox-sensitive protein in oligodendrocytes that results in regulation of MBP phosphorylation? One possibility is $\mathrm{PKC}$ because the increase in MBP phosphorylation was blocked by chelerythrine. In support of this, reactive oxygen species increase the activity of PKC in vitro (Gopalakrishna and Anderson, 1989; Larsson and Cerutti, 1989; Palumbo et al., 1992) and during hippocampal LTP (Klann et al., 1998). Interestingly, the PKC isoforms identified in myelin, $\alpha, \beta I I$, and $\epsilon$, have been shown to be activated by reactive oxygen species in vitro (Knapp and Klann, 1997). Alternatively, reactive oxygen species could activate a protein upstream of PKC. Voltage-gated calcium channels are possible candidates because these are found in oligodendrocytes and regulated by reactive oxygen species in a variety of cells (for review, see Verkhratsky and Kettenmann, 1996; Kourie, 1998). Thus, the reactive oxygen species could act by direct effects on PKC or by increasing calcium levels to activate PKC.

\section{Neuron-glia signaling in the CNS}

Classically considered inert, glial cells are becoming increasingly appreciated as active members of the signaling systems used in the nervous system. Neuronal activity has been found to have a variety of effects on glial cells. In the optic nerve, repetitive 
axonal activity triggers calcium spikes in the surrounding glial cells (Kriegler and Chiu, 1993; Chiu and Kriegler, 1994). MBP phosphorylation has also been found to be regulated by PKC during prolonged high-frequency action potential propagation in the optic nerve (Murray and Steck, 1983, 1984). In hippocampal slices, low-frequency stimulation of the mossy fiber pathway or the Schaffer collateral-commissural pathway elicits calcium oscillations that propagate among astrocytes (Dani et al., 1992; Porter and McCarthy, 1996; Verkhratsky and Kettenmann, 1996). A variety of neurotransmitters applied to oligodendrocytes increase intracellular calcium (Takeda et al., 1995), and neuronal activity can lead to depolarization of oligodendrocytes (Orkand et al., 1966). Axon-glia communication is also an element of development. During myelinogenesis, myelin sheath thickness and internodal length are regulated by axon caliber (Waxman and Black, 1995). Moreover, suppression of internodal sodium channels in axons requires myelin ensheathement (Salzer, 1997). Thus, the pathway delineated in these studies, neuron-glia signaling in area CA1 of the hippocampus, is one example of the numerous conversations between neurons and glial cells that begins during development and lasts through maturity of the nervous system.

Nonsynaptic communication is a dialogue between two cells to accomplish a physiological goal that cannot be achieved through standard synaptic transmission. Mature oligodendrocytes have a relative scarcity of receptors and ion channels and are not synaptically coupled to neurons (Verkhratsky and Kettenmann, 1996). Intercellular messengers, such as reactive oxygen and nitrogen species, provide a viable alternative means of communication between neurons and oligodendrocytes for integrative cellular functioning in an efficient and effective manner. Thus, neuron-glia signaling in the hippocampus during periods of increased neuronal activity may provide a dynamic intercellular communication network in the final output fibers of the hippocampus.

\section{REFERENCES}

Andersen P (1975) Organization of hippocampal neurons and their interconnections. In: The hippocampus (Isaacson RL, Pribham KH, eds). New York: Plenum.

Atkins CM, Chen SJ, Klann E, Sweatt JD (1997) Increased phosphorylation of myelin basic protein during hippocampal long-term potentiation. J Neurochem 68:1960-1967.

Bach-y-Rita P (1993) Nonsynaptic diffusion neurotransmission (NDN) in the brain. Neurochem Int 23:297-318.

Barres BA, Chun LL, Corey DP (1988) Ion channel expression by white matter glia. I. Type 2 astrocytes and oligodendrocytes. Glia 1:10-30.

Beckman JS, Beckman TW, Chen J, Marshall PA, Freeman BA (1990) Apparent hydroxyl radical production by peroxynitrite: implications for endothelial injury from nitric oxide and superoxide. Proc Natl Acad Sci USA 87:1620-1624.

Berger T, Schnitzer J, Kettenmann H (1991) Developmental changes in the membrane current pattern, $\mathrm{K}^{+}$buffer capacity, and morphology of glial cells in the corpus callosum slice. J Neurosci 11:3008-3024.

Bindokas VP, Jordan J, Lee CC, Miller RJ (1996) Superoxide production in rat hippocampal neurons: selective imaging with hydroethidine. J Neurosci 16:1324-1336.

Bito H, Deisseroth K, Tsien RW (1996) CREB phosphorylation and dephosphorylation: a $\mathrm{Ca}(2+)$-and stimulus duration-dependent switch for hippocampal gene expression. Cell 87:1203-1214.

Böhme GA, Bon C, Stutzmann J-M, Doble A, Blanchard J-C (1991) Possible involvement of nitric oxide in long-term potentiation. Eur J Pharmacol 199:379-381.

Chetkovich DM, Klann E, Sweatt JD (1993) Nitric oxide synthaseindependent long-term potentiation in area CA1 of hippocampus. NeuroReport 4:919-922.
Chiu SY, Kriegler S (1994) Neurotransmitter-mediated signaling between axons and glial cells. Glia 11:191-200.

Connor JR, Snyder BS, Beard JL, Fine RE, Mufson EJ (1992) Regional distribution of iron and iron-regulatory proteins in the brain in aging and Alzheimer's disease. J Neurosci Res 31:327-335.

Connors BW, Benardo LS, Prince DA (1983) Coupling between neurons of the developing rat neocortex. J Neurosci 3:773-782.

Dani JW, Chernjavsky A, Smith SJ (1992) Neuronal activity triggers calcium waves in hippocampal astrocyte networks. Neuron 8:429-440.

Daniel H, Hemart N, Jaillard D, Crepel F (1993) Long-term depression requires nitric oxide and guanosine $3^{\prime}: 5^{\prime}$ cyclic monophosphate production in rat cerebellar Purkinje cells. Eur J Neurosci 5:1079-1082.

De Vente J, Hopkins DA, Markerink-Van Ittersum M, Emson PC, Schmidt HH, Steinbusch HW (1998) Distribution of nitric oxide synthase and nitric oxide-receptive, cyclic GMP-producing structures in the rat brain. Neuroscience 87:207-241.

Dermietzel R (1998) Gap junction wiring: a "new" principle in cell-tocell communication in the nervous system? Brain Res Rev 26:176-183.

Dinerman JL, Dawson TM, Schell MJ, Snowman A, Snyder SH (1994) Endothelial nitric oxide synthase localized to hippocampal pyramidal cells: implications for synaptic plasticity. Proc Natl Acad Sci USA 91:4214-4218.

DiPolo R, Beauge L (1987) Characterization of the reverse $\mathrm{Na} / \mathrm{Ca}$ exchange in squid axons and its modulation by $\mathrm{Ca}_{\mathrm{i}}$ and ATP. $\mathrm{C}_{\mathrm{ai}^{-}}$ dependent $\mathrm{N}_{\mathrm{ai}} / \mathrm{C}_{\mathrm{ao}}$ and $\mathrm{N}_{\mathrm{ai}} / \mathrm{N}_{\mathrm{ao}}$ exchange modes. $\mathrm{J}$ Gen Physiol 90:505-525.

Esch F, Lin KI, Hills A, Zaman K, Baraban JM, Chatterjee S, Rubin L, Ash DE, Ratan RR (1998) Purification of a multipotent antideath activity from bovine liver and its identification as arginase: nitric oxide-independent inhibition of neuronal apoptosis. J Neurosci 18:4083-4095.

Fridovich I (1978) The biology of oxygen radicals. Science 201:875-880.

Fridovich I (1989) Superoxide dismutases. An adaptation to a paramagnetic gas. J Biol Chem 264:7761-7764.

Gahtan E, Auerbach JM, Groner Y, Segal M (1998) Reversible impairment of long-term potentiation in transgenic $\mathrm{Cu} / \mathrm{Zn}-\mathrm{SOD}$ mice. Eur J Neurosci 10:538-544.

Gerber MR, Connor JR (1989) Do oligodendrocytes mediate iron regulation in the human brain? Ann Neurol 26:95-98.

Gopalakrishna R, Anderson WB (1989) Calcium- and phospholipidindependent activation of protein kinase $\mathrm{C}$ by selective oxidative modification of the regulatory domain. Proc Natl Acad Sci USA $86: 6758-6762$

Haley JE, Wilcox GL, Chapman PF (1992) The role of nitric oxide in hippocampal long-term potentiation. Neuron 8:211-216.

Halliwell B (1992) Reactive oxygen species and the central nervous system. J Neurochem 59:1609-1623.

Hartman BK, Agrawal HC, Kalmbach S, Shearer WT (1979) A comparative study of the immunohistochemical localization of basic protein to myelin and oligodendrocytes in rat and chicken brain. J Comp Neurol 188:273-290.

Herbert JM, Augereau JM, Gleye J, Maffrand JP (1990) Chelerythrine is a potent and specific inhibitor of protein kinase C. Biochem Biophys Res Commun 172:993-999.

Huang KP, Chan KJ, Singh TJ, Nakabayashi H, Huang FL (1986) Autophosphorylation of rat brain $\mathrm{Ca}^{2+}$-activated and phospholipiddependent protein kinase. J Biol Chem 261:12134-12140.

Huie RE, Padmaja S (1993) The reaction of NO with superoxide. Free Radic Res Commun 18:195-199.

Jefferys JG (1995) Nonsynaptic modulation of neuronal activity in the brain: electric currents and extracellular ions. Physiol Rev 75:689-723.

Kantor DB, Lanzrein M, Stary SJ, Sandoval GM, Smith WB, Sullivan BM, Davidson N, Schuman EM (1996) A role for endothelial NO synthase in LTP revealed by adenovirus-mediated inhibition and rescue. Science 274:1744-1748.

Klann E, Roberson ED, Knapp LT, Sweatt JD (1998) A role for superoxide in protein kinase $\mathrm{C}$ activation and induction of long-term potentiation. J Biol Chem 273:4516-4522.

Knapp LT, Klann E (1997) Regulation of PKC and LTP by reactive oxygen species. Soc Neurosci Abstr 23:1394.

Kourie JI (1998) Interaction of reactive oxygen species with ion transport mechanisms. Am J Physiol 275:C1-C24.

Kriegler S, Chiu SY (1993) Calcium signaling of glial cells along mammalian axons. J Neurosci 13:4229-4245.

Larsson R, Cerutti P (1989) Translocation and enhancement of phos- 
photransferase activity of protein kinase $\mathrm{C}$ following exposure in mouse epidermal cells to oxidants. Cancer Res 49:5627-5632.

Lynch MA, Errington ML, Bliss TV (1989) Nordihydroguaiaretic acid blocks the synaptic component of long-term potentiation and the associated increases in release of glutamate and arachidonate: an in vivo study in the dentate gyrus of the rat. Neuroscience 30:693-701.

Lynch MA, Clements MP, Voss KL, Bramham CR, Bliss TVP (1991) Is arachidonic acid a retrograde messenger in long-term potentiation? Biochem Soc Trans 19:391-396.

Lynch RE, Fridovich I (1978) Permeation of the erythrocyte stroma by superoxide radical. J Biol Chem 253:4697-4699.

Mao GD, Poznansky MJ (1992) Electron spin resonance study on the permeability of superoxide radicals in lipid bilayers and biological membranes. FEBS Lett 305:233-236.

McCord JM (1985) Oxygen-derived free radicals in post-ischemic tissue injury. N Engl J Med 312:159-163.

Meves H, Vogel W (1973) Calcium inward currents in internally perfused giant axons. J Physiol (Lond) 235:225-265.

Milner B, Squire LR, Kandel ER (1998) Cognitive neuroscience and the study of memory. Neuron 20:445-468.

Monuki ES, Lemke G (1995) Molecular biology of myelination. In: The axon (Waxman SG, Kocsis JD, Stys PK, eds). New York: Oxford UP.

Mullins LJ, Requena J, Whittembury J (1985) $\mathrm{Ca}^{2+}$ entry in squid axons during voltage-clamp pulses is mainly $\mathrm{Na}^{+} / \mathrm{Ca}^{2+}$ exchange. Proc Natl Acad Sci USA 82:1847-1851.

Murray N, Steck AJ (1983) Depolarizing agents regulate the phosphorylation of myelin basic protein in rat optic nerves. J Neurochem 41:543-548.

Murray N, Steck AJ (1984) Impulse conduction regulates myelin basic protein phosphorylation in rat optic nerve. J Neurochem 43:243-248.

O'Dell TJ, Hawkins RD, Kandel ER, Arancio O (1991) Tests of the roles of two diffusible substances in long-term potentiation: Evidence for nitric oxide as a possible early retrograde messenger. Proc Natl Acad Sci USA 88:11285-11289.

O'Dell TJ, Huang PL, Dawson TM, Dinerman JL, Snyder SH, Kandel ER, Fishman MC (1994) Endothelial NOS and the blockade of LTP by NOS inhibitors in mice lacking neuronal NOS. Science 265:542-546.

Orkand RK, Nicholls JG, Kuffler SW (1966) Effect of nerve impulses on the membrane potential of glial cells in the central nervous system of amphibia. J Neurophysiol 29:788-806.

Palumbo EJ, Sweatt JD, Chen S-J, Klann E (1992) Oxidation-induced persistent activation of protein kinase $\mathrm{C}$ in hippocampal homogenates. Biochem Biophys Res Commun 187:1439-1445.

Peinado A, Yuste R, Katz LC (1993) Gap junctional communication and the development of local circuits in neocortex. Cereb Cortex 3:488-498.

Porter JT, McCarthy KD (1996) Hippocampal astrocytes in situ respond to glutamate released from synaptic terminals. J Neurosci 16:5073-5081.

Pou S, Pou WS, Bredt DS, Snyder SH, Rosen GM (1992) Generation of superoxide by purified brain nitric oxide synthase. J Biol Chem 267:24173-24176.

Radi R, Beckman JS, Bush KM, Freeman BA (1991) Peroxynitrite oxidation of sulfhydryls. The cytotoxic potential of superoxide and nitric oxide. J Biol Chem 266:4244-4250.

Roberson ED, Sweatt JD (1996) Transient activation of cyclic AMPdependent protein kinase during long-term potentiation. J Biol Chem 271:30436-30441.

Roberson ED, English JD, Sweatt JD (1996) A biochemist's view of long-term potentiation. Learn Mem 3:1-24.

Rumyantseva GV, Weiner LM, Molin YN, Budker VG (1979) Permeation of liposome membrane by superoxide radical. FEBS Lett 108:477-480
Salzer JL (1997) Clustering sodium channels at the node of Ranvier: close encounters of the axon-glia kind. Neuron 18:843-846.

Schuman EM, Madison DV (1994) Locally distributed synaptic potentiation in the hippocampus. Science 263:532-536.

Shibuki K, Okada D (1991) Endogenous nitric oxide release required for long-term synaptic depression in the cerebellum. Nature 349:326-328.

Snow RW, Dudek FE (1984) Synchronous epileptiform bursts without chemical transmission in CA2, CA3 and dentate areas of the hippocampus. Brain Res 298:382-385.

Soliven B, Szuchet S, Arnason BG, Nelson DJ (1988) Voltage-gated potassium currents in cultured ovine oligodendrocytes. J Neurosci 8:2131-2141.

Son H, Hawkins RD, Martin K, Kiebler M, Huang PL, Fishman MC, Kandel ER (1996) Long-term potentiation is reduced in mice that are doubly mutant in endothelial and neuronal nitric oxide synthase. Cell 87:1015-1023.

Sontheimer H, Trotter J, Schachner M, Kettenmann H (1989) Channel expression correlates with differentiation stage during the development of oligodendrocytes from their precursor cells in culture. Neuron 2:1135-1145.

Stys PK, Lopachin RM (1998) Mechanisms of calcium and sodium fluxes in anoxic myelinated central nervous system axons. Neuroscience 82:21-32.

Takeda M, Nelson DJ, Soliven B (1995) Calcium signaling in cultured rat oligodendrocytes. Glia 14:225-236.

Tamamaki N, Nojyo Y (1991) Crossing fiber arrays in the rat hippocampus as demonstrated by three-dimensional reconstruction. J Comp Neurol 303:435-442.

Vanhatalo S, Soinila S (1998) The concept of chemical neurotransmission-variations on the theme. Ann Med 30:151-158.

Verkhratsky A, Kettenmann H (1996) Calcium signalling in glial cells. Trends Neurosci 19:346-352.

Waxman SG, Black JA (1995) Axoglial interactions at the cellular and molecular levels in central nervous system myelinated fibers. In: Neuroglia (Kettenmann H, Ransom BR, eds). New York: Oxford UP.

Waxman SG, Ritchie JM (1993) Molecular dissection of the myelinated axon. Ann Neurol 33:121-136.

Wendland B, Schweizer FE, Ryan TA, Nakane M, Murad F, Scheller RH, Tsien RW (1994) Existence of nitric oxide synthase in rat hippocampal pyramidal cells. Proc Natl Acad Sci USA 91:2151-2155.

Westrum LE, Blackstad TW (1962) An electron microscopic study of the stratum radiatum of the rat hippocampus (regio superior, CA1) with particular emphasis on synaptology. J Comp Neurol 119:281-309.

Williams JH, Bliss TVP (1989) An in vitro study of the effect of lipoxygenase and cyclooxygenase inhibitors of arachidonic acid on the induction and maintenance of long-term potentiation in the hippocampus. Neurosci Lett 107:301-306.

Williams JH, Li Y-G, Nayak A, Errington ML, Murphy KP, Bliss TVP (1993) The suppression of long-term potentiation in rat hippocampus by inhibitors of nitric oxide synthase is temperature and age dependent. Neuron 11:877-884.

Wilson RI, Yanovsky J, Godecke A, Stevens DR, Schrader J, Haas HL (1997) Endothelial nitric oxide synthase and LTP. Nature 386:338.

Xia Y, Dawson VL, Dawson TM, Snyder SH, Zweier JL (1996) Nitric oxide synthase generates superoxide and nitric oxide in argininedepleted cells leading to peroxynitrite-mediated cellular injury. Proc Natl Acad Sci USA 93:6770-6774.

Xia Y, Tsai AL, Berka V, Zweier JL (1998) Superoxide generation from endothelial nitric-oxide synthase. A $\mathrm{Ca}^{2+} /$ calmodulin-dependent and tetrahydrobiopterin regulatory process. J Biol Chem 273:25804-25808. 